\title{
Radiosurgery and fractionated stereotactic body radiotherapy for patients with lung oligometastases
}

Goda G. Kalinauskaite ${ }^{1,2^{*}} \mathbb{D}$, Ingeborg I. Tinhofer ${ }^{1,3}$, Markus M. Kufeld ${ }^{2}$, Anne A. Kluge ${ }^{1,2}$, Arne A. Grün ${ }^{1,2}$, Volker V. Budach ${ }^{1,2}$, Carolin C. Senger ${ }^{1,2+}$ and Carmen C. Stromberger ${ }^{1,2 \dagger}$

\begin{abstract}
Background: Patients with oligometastatic disease can potentially be cured by using an ablative therapy for all active lesions. Stereotactic body radiotherapy (SBRT) is a non-invasive treatment option that lately proved to be as effective and safe as surgery in treating lung metastases (LM). However, it is not clear which patients benefit most and what are the most suitable fractionation regimens. The aim of this study was to analyze treatment outcomes after single fraction radiosurgery (SFRS) and fractionated SBRT (FSBRT) in patients with lung oligometastases and identify prognostic clinical features for better survival outcomes.
\end{abstract}

Methods: Fifty-two patients with 94 LM treated with SFRS or fSBRT between 2010 and 2016 were analyzed. The characteristics of primary tumor, LM, treatment, toxicity profiles and outcomes were assessed. Kaplan-Meier and Cox regression analyses were used for estimation of local control (LC), overall survival (OS) and progression-free survival.

Results: Ninety-four LM in 52 patients were treated using SFRS/FSBRT with a median of 2 lesions per patient (range: 1-5). The median planning target volume (PTV)-encompassing dose for SFRS was 24 Gy (range: 17-26) compared to 45 Gy (range: 20-60) in 2-12 fractions with fSBRT. The median follow-up time was 21 months (range: 3-68). LC rates at 1 and 2 years for SFSR vs. fSBRT were 89 and $83 \%$ vs. 75 and 59\%, respectively $(p=0.026)$. LM treated with SFSR were significantly smaller $(p=0.001)$. The 1 and 2-year OS rates for all patients were 84 and $71 \%$, respectively. In univariate analysis treatment with SFRS, an interval of $\geq 12$ months between diagnosis of LM and treatment, noncolorectal cancer histology and BED < 100 Gy were significantly associated with better LC. However, none of these parameters remained significant in the multivariate Cox regression model. OS was significantly better in patients with negative lymph nodes (NO), Karnofsky performance status (KPS) $>70 \%$ and time to first metastasis $\geq 12$ months. There was no grade 3 acute or late toxicity.

Conclusions: Longer time to first metastasis, good KPS and NO predicted better OS. Good LC and low toxicity rates were achieved after short SBRT schedules.

Keywords: Oligometastases, SBRT, Radiosurgery, Lung metastases, CyberKnife

\footnotetext{
* Correspondence: goda.kalinauskaite@charite.de

${ }^{\dagger} \mathrm{C}$. Senger and C. Stromberger contributed equally to this work.

'Department of Radiation Oncology and Radiotherapy, Charité -

Universitätsmedizin Berlin, Augustenburger Platz 1, 13353 Berlin, Germany

${ }^{2}$ Charité Cyberknife Center, Charité - Universitätsmedizin Berlin,

Augustenburger Platz 1, 13353 Berlin, Germany

Full list of author information is available at the end of the article
}

(C) The Author(s). 2020 Open Access This article is licensed under a Creative Commons Attribution 4.0 International License, which permits use, sharing, adaptation, distribution and reproduction in any medium or format, as long as you give appropriate credit to the original author(s) and the source, provide a link to the Creative Commons licence, and indicate if changes were made. The images or other third party material in this article are included in the article's Creative Commons licence, unless indicated otherwise in a credit line to the material. If material is not included in the article's Creative Commons licence and your intended use is not permitted by statutory regulation or exceeds the permitted use, you will need to obtain permission directly from the copyright holder. To view a copy of this licence, visit http://creativecommons.org/licenses/by/4.0/ The Creative Commons Public Domain Dedication waiver (http://creativecommons.org/publicdomain/zero/1.0/) applies to the data made available in this article, unless otherwise stated in a credit line to the data. 


\section{Background}

Metastatic progression of cancer is linked to poor prognosis and is the leading cause of cancer-related deaths [1]. Few decades ago, the diagnosis of metastatic disease was related to lethal outcomes. This paradigm has changed after Hellman and Weichselbaum introduced the concept of oligometastases: the intermediate state between non-metastatic cancer and highly palliative disseminated metastatic disease [2]. Patients with an initially limited number of metastases or with progression of only few lesions after cytoreductive therapy might be potentially cured or reach long-term survival when treated with local ablation therapy for all lesions. The search for prognostic biomarkers for discrimination of potentially oligometastatic patients is still ongoing. In some small prospective studies circulating tumor cells as well as circulating tumor DNA in liquid biopsies were able to predict treatment outcomes and response to ablative therapy [3]. However, until prognostic biomarkers will be established for routine application, the selection of patients that could benefit from local ablative therapy rather than from palliation will be based on clinical features.

The lungs are one of the most common metastatic sites for various solid tumors [4, 5]. Stereotactic body radiotherapy (SBRT) and surgical resection are frequently used treatment options for patients with a limited number of pulmonary lesions. Although SBRT compared to surgery for lung metastases have not been studied in a prospective randomized trial, retrospective data suggest that both methods achieve equal results in terms of local control and overall survival $[6,7]$. Single fraction radiosurgery (SFRS) is especially attractive as an outpatient procedure in terms of patients' compliance, cost effectiveness and limited treatment time. However, up to now there is no recommendation when to administer SFRS over fractionated SBRT (fSBRT). The aim of this study was to analyze local control (LC) after SFRS and ASBRT in patients with lung oligometastases and identify prognostic clinical features for better survival outcomes.

\section{Methods}

\section{Study design}

This retrospective study was approved by the institutional medical ethics committee of the Charité - Universitätsmedizin Berlin (EA1/214/16). We identified all patients with lung metastases treated with curative intended SFRS or fSBRT between January 2010 and December 2016. Cases with an initially limited number of lung metastases from various solid tumors or with oligo-progression after systemic therapy were selected for the study. Patients with disseminated disease or with a second malignancy were excluded. The data on patients' demographics, e.g. primary tumor and metastases, disease stage as determined by computed tomography (CT), magnetic resonance imaging or positron emission tomography, treatment parameters, follow-up and LC, overall survival (OS), progression-free survival (PFS), distant metastases-free survival (DMFS) were calculated. Clinical follow-up was performed at 6 weeks after SFRS/fSBRT and at 3, 6, 12, 18, and 24 months after treatment and annually thereafter. Acute and late adverse events were scored using NCI Common Terminology Criteria for Adverse Events (CTCAE), version 4.0.

\section{Treatment planning and delivery}

SBRT was delivered using CyberKnife (CK) and Novalis systems, both dedicated stereotactic linear accelerators. For respiratory motion compensation, the CyberKnife Synchrony ${ }^{\bullet}$ Respiratory Motion Tracking System was used. In general, one gold fiducial $(1.0 \mathrm{~mm} \times 5.0 \mathrm{~mm})$ was placed centrally within the lung metastasis under CT-guidance in local anesthesia. For lesions larger than $2 \mathrm{~cm}$ feasibility of X-sight lung tracking was evaluated. If motion compensation was not possible (e.g. due to patients' comorbidities or technical limitations) an internal gross tumor volume (IGTV), defined as the gross tumor volumes of all respiratory phases on a $4 \mathrm{D}$ CT was constructed. In these cases, patients were aligned on the spine. High-resolution thin-slice native planning CT of the chest with 1.0 to $2.0 \mathrm{~mm}$ slice thickness in supine position was performed.

The gross tumor volume (GTV) was delineated on all axial slices including spiculae in the lung window. The clinical target volume (CTV) was equal to the GTV. The planning target volume (PTV) was obtained by adding a 5-8 $\mathrm{mm}$ margin to the CTV.

For CK treatments, doses were prescribed to the $70 \%$ isodose covering the PTV and a total maximum of $100 \%$. Novalis treatment was planned with less inhomogeneous dose distributions with the $80 \%$ isodose line of the prescribed $100 \%$ dose encompassing the PTV and allowing a maximum of up to $110 \%$ (Fig. 1).

The linear-quadratic model, assuming an alpha/beta ratio of $10 \mathrm{~Gy}$ for tumor, was used to calculate the biologically equivalent dose (BED) and the equivalent dose in 2 Gy fractions (EQD2) for PTV-encompassing total dose. Dose constraints to organs at risk for single fraction treatment are shown in Table 1. Treatment planning for CK was performed in Multiplan ${ }^{\circledR}$ (Accuray) using the Ray-Trace or Monte Carlo algorithm and for Novalis in iPlan $^{\odot}$ (BrainLAB) using the Pencil Beam algorithm.

\section{Endpoints and statistical considerations}

LC was defined as time from SFRS/fSBRT to tumor progression within the irradiation field or absence of 


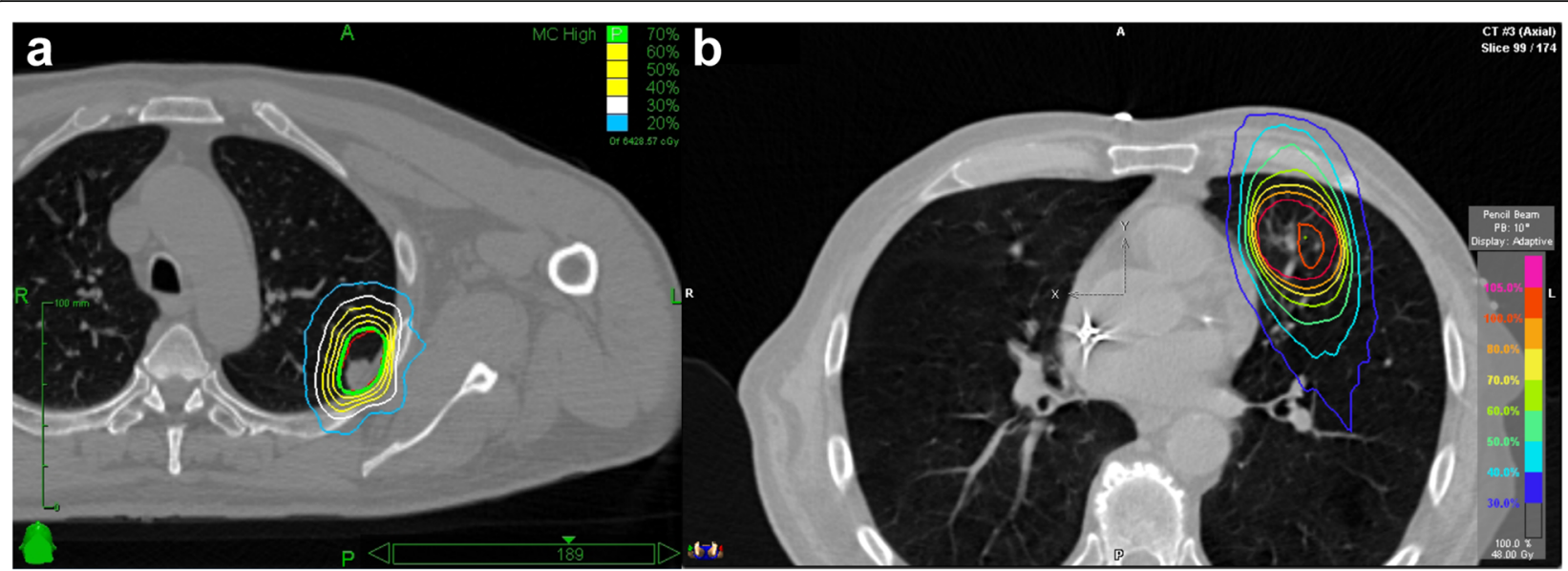

Fig. 1 Treatment plan and dose distribution for (a) CyberKnife, (b) Novalis treatment system

progression at last available follow-up. LC was assessed using routinely CT scans every 3 months. PET-CT and/ or biopsy of irradiated metastasis was performed in cases of uncertain progression detected on CT images. OS was calculated from the beginning of SFRS or FSBRT until the death of any cause or the date of last follow-up. The time to new metastases in the lung outside of the SFRS/ fSBRT field or in other organs was defined as DMFS and was calculated from the start of SFRS/fSBRT. PFS was defined as the time from the start of SFRS/fSBRT until progression of the primary tumor, development of new metastases or local failure.

LC was compared between lung metastases treated with SFRS and fSBRT. The different fractionation regimens in the same patient were allowed, thus fractionation impact on OS, PFS and DMFS could not be assessed.

OS, LC, DMFS and PFS after SFRS/fSBRT for lung metastases were calculated using the Kaplan-Meier method. Cox-regression analysis was used to obtain the Hazard Ratio (HR) and 95\% confidence intervals (CI) for

Table 1 Dose constrains for organs at risk of single fraction radiosurgery

\begin{tabular}{llll}
\hline Organs at risk & $\begin{array}{l}\text { Max critical volume } \\
\text { above threshold }\left(\mathrm{cm}^{3}\right)\end{array}$ & $\begin{array}{l}\text { Threshold } \\
\text { dose }(\mathrm{Gy})\end{array}$ & $\begin{array}{l}\text { Max point } \\
\text { dose }(\mathrm{Gy})^{\mathrm{a}}\end{array}$ \\
\hline Spinal cord & $<0.35$ & 10.0 & 14.0 \\
Esophagus & $<5$ & 11.9 & 15.4 \\
$\begin{array}{l}\text { Hearts/ } \\
\text { pericardium }\end{array}$ & $<15$ & 16.0 & 22.0 \\
$\begin{array}{l}\text { Great vessels } \\
\text { Trachea and }\end{array}$ & $<10$ & 31.0 & 37.0 \\
$\begin{array}{l}\text { large bronchus } \\
\text { Rib }\end{array}$ & $<1$ & 10.5 & 20.2 \\
$\begin{array}{l}\text { Ipsilateral Lung } \\
\text { (mean) }\end{array}$ & - & 22.0 & 30.0 \\
\hline
\end{tabular}

Point defined as $0.035 \mathrm{~cm}^{3}$ or less various covariates. Covariates with a $p$-value of $\leq 0.1$ were included into the multivariate analyses carried out with a Cox proportional hazards model with a threshold of $p<0.05$. The chi-squared test was performed in order to compare variables between groups. A p-value of < 0.05 was considered as statistically significant. The data processing and statistical analyses were accomplished using FileMaker Pro 15 Advanced, Excel 2010 and IBM SPSS Statistics 24 (SPSS Inc., Chicago, IL, USA).

\section{Results}

\section{Patient and tumor characteristics}

The clinical, treatment and follow-up data of 52 eligible patients were assessed. Thirty-two patients were male $(61.5 \%)$ and 20 were female (38.5\%) with a median age of 66 years (range: 26-84) and a median Karnofsky performance status (KPS) of 80\% (range: 60-100). The most prevalent primary tumor was colorectal cancer (CRC) in 17 patients (32.7\%). PET-CT staging before the SBRT for lungs was performed in 7 (13.5\%) patients. Twelve patients (23.1\%) had oligometastases at the time of tumor diagnosis. The median time to first metastasis was 19.5 months (range: $0-37.9)$. In 37 patients $(71.2 \%$ ) metastases were limited to the lungs. Eight patients (15.4\%) had additional liver metastases and 3 patients $(5.8 \%)$ had brain metastasis. Forty-six patients (88.5\%) had systemic therapy prior to lung SBRT and 15 (28.8\%) after lung SBRT. Seventeen patients (32.7\%) received immunotherapy at any time during the disease course. $\mathrm{Pa}$ tients' and primary tumor characteristics are shown in Table 2.

\section{Treatment characteristics}

Overall, 94 lung metastases were treated using SFRS/ fSBRT with a median of 2 lesions per patient (range: 15). Metastases and SFRS/fSBRT characteristics are shown in Table 3 and Table 4. Forty-five metastases 
Table 2 Patient and primary tumor characteristics

\begin{tabular}{|c|c|}
\hline Characteristics & No. (\%) \\
\hline \multicolumn{2}{|l|}{ Age, years } \\
\hline Median & 66 \\
\hline Range & $26-84$ \\
\hline \multicolumn{2}{|l|}{ Gender } \\
\hline Female & $20(38.5)$ \\
\hline Male & $32(61.5)$ \\
\hline \multicolumn{2}{|l|}{ KPS (\%) } \\
\hline Median & 80 \\
\hline Range & $60-100$ \\
\hline \multicolumn{2}{|c|}{ Primary tumor type } \\
\hline CRC & $17(32.7)$ \\
\hline Sarcoma & $8(15.4)$ \\
\hline Melanoma & $7(13.5)$ \\
\hline HNC & $6(11.5)$ \\
\hline $\mathrm{RCC}$ & $5(9.6)$ \\
\hline NSCLC & $3(5.8)$ \\
\hline Others & $6(11.5)$ \\
\hline \multicolumn{2}{|c|}{ T-classification at initial diagnosis } \\
\hline $\mathrm{T} \leq 2$ & $17(32.7)$ \\
\hline$T>2$ & $30(57.7)$ \\
\hline Unknown & $5(9.6)$ \\
\hline \multicolumn{2}{|c|}{ N-classification at initial diagnosis } \\
\hline NO & $18(34.6)$ \\
\hline $\mathrm{N}+$ & $26(50.0)$ \\
\hline Unknown & $8(15.4)$ \\
\hline \multicolumn{2}{|c|}{ M-classification at initial diagnosis } \\
\hline MO & $36(69.2)$ \\
\hline M1 & $12(23.1)$ \\
\hline Unknown & $4(7.7)$ \\
\hline \multicolumn{2}{|c|}{ Pre-SFRS/fSBRT systemic therapy } \\
\hline Yes & $46(88.5)$ \\
\hline No & $6(11.5)$ \\
\hline \multicolumn{2}{|c|}{ No. of LM treated with SFRS/fSBRT per patient } \\
\hline Median & 2 \\
\hline Range & $1-5$ \\
\hline \multicolumn{2}{|c|}{ No. of affected organs per patient } \\
\hline Median & 1 \\
\hline Range & $1-4$ \\
\hline
\end{tabular}

(47.9\%) were treated with SFRS of which only 12 were located centrally. Metastases treated with fSBRT were almost equally distributed with respect to location (24
Table 3 Metastases and treatment characteristics

\begin{tabular}{|c|c|c|c|}
\hline LM and treatment characteristics & $\begin{array}{l}\text { SFRS } \\
(n=45)\end{array}$ & $\begin{array}{l}\text { fSBRT } \\
(n=49)\end{array}$ & $p$-value \\
\hline \multicolumn{4}{|l|}{ Metastasis diameter (mm) } \\
\hline Median & 12.0 & 16.0 & 0.003 \\
\hline Range & $5.0-35.0$ & $5.0-70.0$ & \\
\hline \multicolumn{4}{|l|}{ Metastasis PTV $\left(\mathrm{cm}^{3}\right)$} \\
\hline Median & 9.9 & 24.0 & $<0.001$ \\
\hline Range & $2.4-90.8$ & $5.8-164.5$ & \\
\hline \multicolumn{4}{|l|}{ Metastasis location } \\
\hline peripheral & 32 & 25 & 0.092 \\
\hline central & 13 & 24 & \\
\hline \multicolumn{4}{|c|}{ Metastasis histology (CRC vs. non-CRC) } \\
\hline CRC & 8 & 21 & 0.009 \\
\hline Non-CRC & 37 & 28 & \\
\hline \multicolumn{4}{|c|}{ PTV-encompassing prescription dose (Gy) } \\
\hline Median & 24 & 45 & $<0.001$ \\
\hline Range & $17-26$ & $20-60$ & \\
\hline \multicolumn{4}{|l|}{ PTV-encompassing single dose (Gy) } \\
\hline Median & 24 & 9.6 & $<0.001$ \\
\hline Range & $17-26$ & $4-16$ & \\
\hline \multicolumn{4}{|l|}{ Biological effective dose (Gy) } \\
\hline Median & 81.6 & 105.6 & 0.015 \\
\hline Range & $45.9-93.6$ & $42.6-151.2$ & \\
\hline
\end{tabular}

LM lung metastases, SFRS single fraction radiosurgery, fSBRT fractionated stereotactic body radiotherapy, PTV planning target volume, CRC colorectal cancer

central vs. 25 peripheral). Median diameter of metastases was $14.5 \mathrm{~mm}$ (range: 5-70), with no significant difference between centrally and peripheral located lesions. The median time from the diagnosis of lung metastases to the start of SFRS/fSBRT was 4.5 months (range: 0-

Table 4 Fractionation regimens

\begin{tabular}{llll}
\hline $\begin{array}{l}\text { Fractions and PTV- encompassing } \\
\text { single dose }\end{array}$ & $\begin{array}{l}\text { No. of LM } \\
(\%)\end{array}$ & $\begin{array}{l}\text { BED } \\
(\mathrm{Gy})\end{array}$ & $\begin{array}{l}\text { EQD2 } \\
(\mathrm{Gy})\end{array}$ \\
\hline $1 \times 22$ Gy & $2(2.1)$ & 70.4 & 58.7 \\
$1 \times 24 \mathrm{~Gy}$ & $20(21.3)$ & 81.6 & 68.0 \\
$1 \times 25 \mathrm{~Gy}$ & $12(12.8)$ & 87.5 & 72.9 \\
$1 \times 26 \mathrm{~Gy}$ & $5(5.3)$ & 93.6 & 78.0 \\
$3 \times 12.5 \mathrm{~Gy}$ & $3(3.2)$ & 84.4 & 70.3 \\
$3 \times 15$ Gy & $8(8.5)$ & 112.5 & 93.8 \\
$3 \times 16$ Gy & $9(9.6)$ & 124.8 & 104.0 \\
$4 \times 12$ Gy & $8(8.5)$ & 105.6 & 88.0 \\
$4 \times 9.6$ Gy & $9(9.6)$ & 75.3 & 62.7 \\
$5 \times 8$ Gy & $2(2.1)$ & 72.0 & 60.0 \\
other regimens & $16(17.0)$ & & \\
\hline
\end{tabular}

$L M$ lung metastases, $P T V$ planning target volume, $B E D$ biologically effective dose, EQD2 equivalent dose 
a

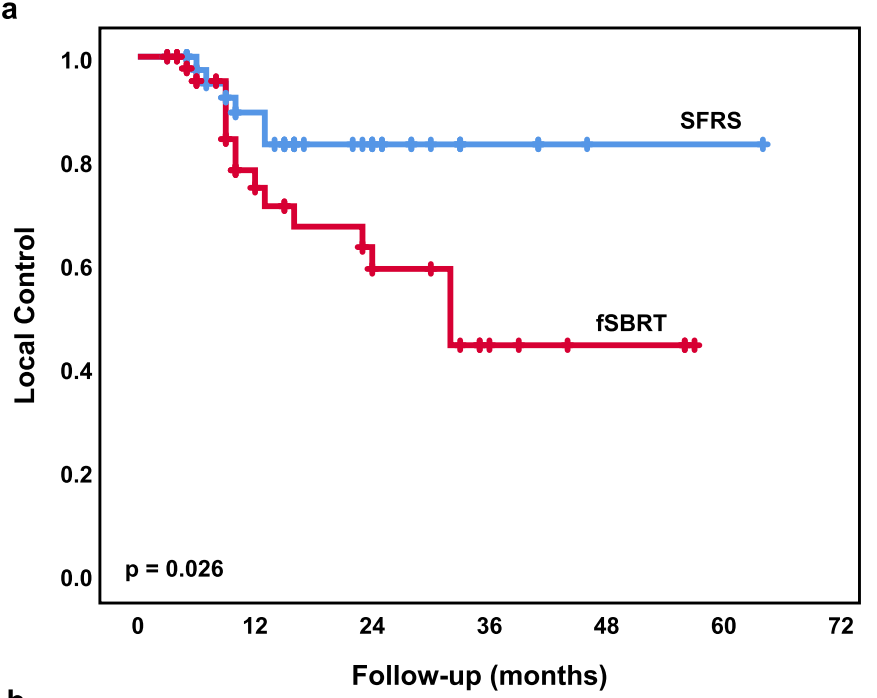

b
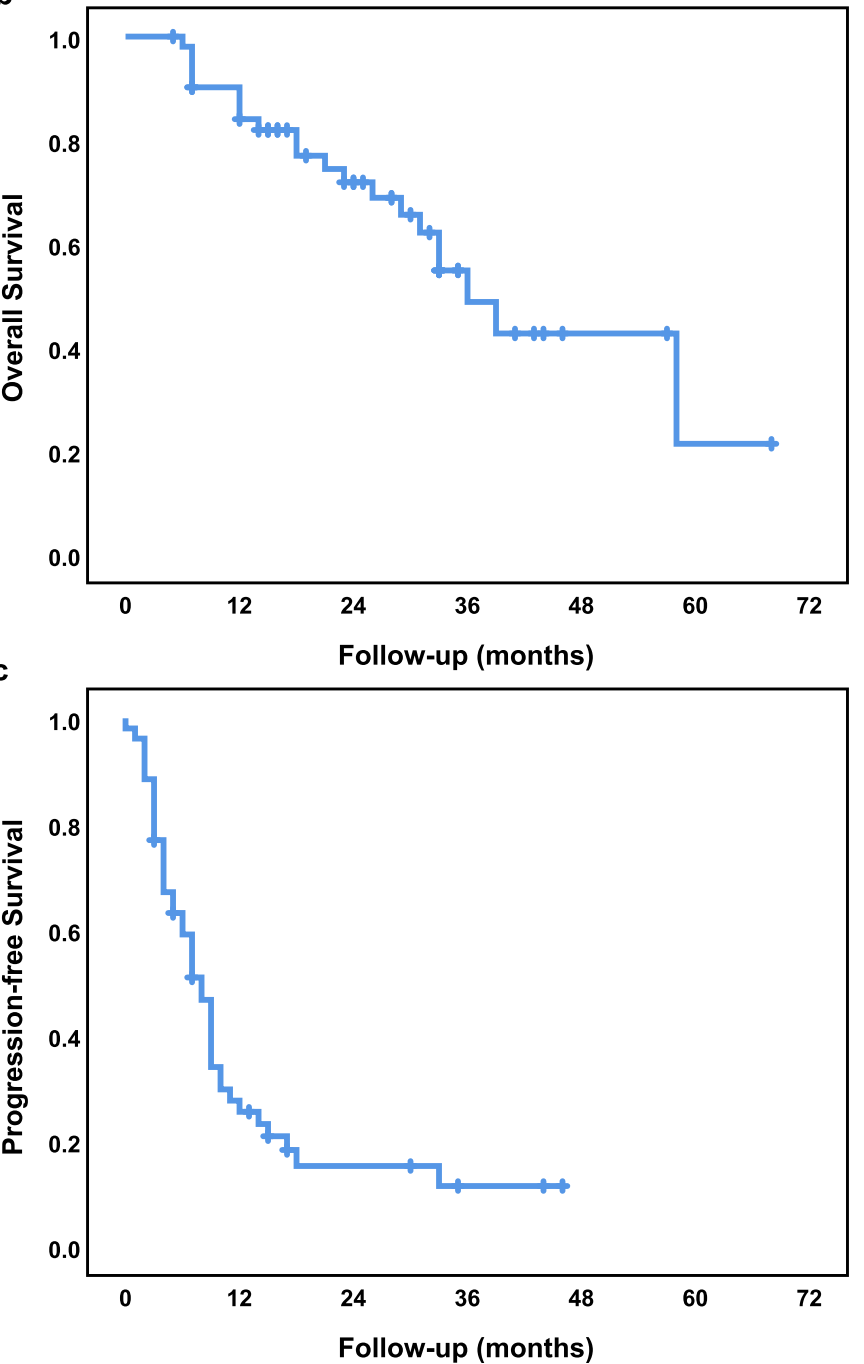

Fig. 2 Kaplan-Meier curves of (a) local control SFRS vs. fSBRT, (b) overall survival, (c) progression-free survival 
61). Before the therapy with CK a gold fiducial was implanted in 51 metastases, whereof 37 were treated with SFRS and 14 with FSBRT using the Synchrony tracking method. A total of 14 lung metastases were treated using the X-sight lung tracking method. IGTV was used for all 29 metastases treated with Novalis. The median prescription dose for SFRS was 24 Gy (range: 17-26) compared to fSBRT with median 45 Gy (range: 20-60) delivered in 2-12 fractions. The median diameter and PTV were significantly smaller in metastases treated with SFRS compared to fSBRT: $12 \mathrm{~mm}$ (range: 5-35) and $9.9 \mathrm{~cm}^{3}$ (range: $2.4-90.8$ ) vs. $16 \mathrm{~mm}$ (range: 5-70) and $24.0 \mathrm{~cm}^{3}$ (range: $5.8-164.5$ ), respectively.

\section{Patient outcomes}

The median follow-up time was 21 months (range: 368 ). The 1-year and 2-year LC rates for SFSR vs. fSBRT were 89 and $83 \%$ vs. 75 and $59 \%$, respectively ( $p=$ 0.026). One and 2-year LC rates for metastases from CRC vs. non-CRC were 59 and $46 \%$ vs. 90 and $80 \%$, respectively $(p=0.001)$. In 5 out of 22 metastases with local progression relapse was confirmed using PET-CT and in 2 after histological examination. Eleven lesions were repeatedly treated with local therapy: either with repeated SBRT or with surgery. One and 2-year OS and PFS rates were 84,71 and $26 \%, 15 \%$, respectively. At the time of analysis 21 patients (41.4\%) were dead. Disease progression occurred in 42 patients (80.8\%), of which 19 patients (36.5\%) developed metastases in new organs. The Kaplan-Meier LC, OS and PFS curves are shown in Fig. 2.

Treatment with SFRS, an interval of $<12$ months between diagnosis of metastases and the beginning of SFRS/fSBRT as well as non-colorectal histology were significantly associated with better LC in univariate analysis (Table 5). However, none of these parameters remained significant in multivariate analysis. N0, KPS $>70 \%$ and time to first metastasis $\geq 12$ months were significantly associated with improved OS. PFS was significantly better in patients with KPS $>70 \%$ and with maximum 3 metastases at the time of SBRT (Table 6). There was no difference regarding survival outcomes between patients with oligorecurence and oligometastases.

\section{Treatment related toxicity}

The SFRS and ASBRT were safe and very well tolerated. No treatment-related deaths and grade $\geq 3$ toxicities occurred. Six patients (11.5\%) developed asymptomatic grade 1 pneumonitis (2 patients after SFRS and 4 patients after fSBRT) and one patient had grade 1 pulmonary fibrosis. Symptomatic and medical intervention requiring grade 2 pneumonitis was diagnosed in one patient (1.9\%) after SFRS with $25 \mathrm{~Gy}$.
Table 5 Univariate analysis of factors influencing local control

\begin{tabular}{|c|c|c|}
\hline Covariate & HR $(95 \% \mathrm{Cl})$ & $p$-value \\
\hline \multicolumn{3}{|c|}{ Time between diagnosis of LM and SBRT (months) } \\
\hline$<12$ & 1 & \\
\hline$\geq 12$ & $2.5(1.1-6.0)$ & 0.027 \\
\hline \multicolumn{3}{|c|}{ Location of LM } \\
\hline central & 1 & \\
\hline peripheral & $0.7(0.2-1.7)$ & 0.412 \\
\hline \multicolumn{3}{|l|}{ Histology } \\
\hline CRC & 1 & \\
\hline non-CRC & $0.2(0.1-0.6)$ & 0.004 \\
\hline \multicolumn{3}{|c|}{ LM diameter (mm) } \\
\hline$\leq 10$ & 1 & \\
\hline$>10$ & $2.2(0.8-6.6)$ & 0.150 \\
\hline \multicolumn{3}{|l|}{ PTV $\left(\mathrm{cm}^{3}\right)$} \\
\hline$\leq 10$ & 1 & \\
\hline$>10$ & $3.3(0.9-11.3)$ & 0.053 \\
\hline \multicolumn{3}{|c|}{ Fractionation regimens } \\
\hline SFRS & 1 & \\
\hline fSBRT & $2.7(1.0-7.0)$ & 0.037 \\
\hline \multicolumn{3}{|l|}{ BED } \\
\hline$<100 G y$ & 1 & \\
\hline$\geq 100$ Gy & $2.7(1.1-6.4)$ & 0.021 \\
\hline
\end{tabular}

HR Hazard ratio, $\mathrm{Cl}$ confidence interval, $L M$. lung metastases, SBRT stereotactic body radiotherapy, SFRS single fraction radiosurgery, $F S B R T$ fractionated stereotactic body radiotherapy, PTV Planning target volume, BED biologically effective dose

\section{Discussion}

This analysis represents a single-center experience in treating oligometastatic lung lesions with curative intended SFRS and fSBRT. The 1-, 2-year LC and OS rates for the entire cohort were 82,70 and $84 \%, 71 \%$, respectively. Our findings are comparable with the current findings in the literature (Table 7) [8-16].

SBRT is an attractive non-invasive treatment option providing good therapy outcomes with minimum toxicity. The BED $\geq 100 \mathrm{~Gy}$, smaller tumor size, shorter interval between diagnosis and treatment of metastases are favorable prognostic factors influencing local control of lung metastases after SBRT [9, 17-19]. The existing data on fractionation schedules as well as dosage of SBRT for lung metastases is limited by retrospective nature or non-randomized prospective study design. Therefore, no standardized treatment regimens are yet available. The primary results of TROG 13.01 SAFRON II Phase II trial which compares SFRS to fSBRT for lung metastases are expected soon [20].

According to our data, small lung metastases (median PTV $\leq 9.9 \mathrm{~cm}^{3}$, median diameter $12 \mathrm{~mm}$ ) might safely be treated with SFRS applying 24-26 Gy (median $D_{\max }$ of 
Table 6 Univariate and multivariate analysis of factors influencing overall and progression-free survival

\begin{tabular}{|c|c|c|c|c|c|c|c|c|}
\hline \multirow[t]{3}{*}{ Covariate } & \multicolumn{4}{|l|}{ Overall survival } & \multicolumn{4}{|c|}{ Progression-free survival } \\
\hline & \multirow{2}{*}{$\begin{array}{l}\text { Univariate analysis } \\
\mathrm{HR}(95 \% \mathrm{Cl})\end{array}$} & \multicolumn{3}{|c|}{ Multivariate analysis } & \multicolumn{2}{|c|}{ Univariate analysis } & \multicolumn{2}{|c|}{ Multivariate analysis } \\
\hline & & $p$-value & HR $(95 \% \mathrm{Cl})$ & $p$-value & $\mathrm{HR}(95 \% \mathrm{Cl})$ & $\overline{p \text {-value }}$ & $\mathrm{HR}(95 \% \mathrm{Cl})$ & $p$-value \\
\hline \multicolumn{9}{|l|}{ Age (years) } \\
\hline$>70$ & 1 & & & & 1 & & & \\
\hline$\leq 70$ & $1.1(0.4-2.7)$ & 0.81 & NA & NA & $0.8(0.4-1.5)$ & 0.56 & NA & NA \\
\hline \multicolumn{9}{|l|}{ Gender } \\
\hline Female & 1 & & & & 1 & & & \\
\hline Male & $1.6(0.6-4.6)$ & 0.31 & NA & NA & $1.2(0.8-1.6)$ & 0.25 & NA & NA \\
\hline \multicolumn{9}{|c|}{ Primary tumor } \\
\hline non-CRC & 1 & & & & 1 & & & \\
\hline CRC & $0.6(0.2-1.4)$ & 0.29 & NA & NA & $0.8(0.5-1.6)$ & 0.64 & NA & NA \\
\hline \multicolumn{9}{|l|}{ KPS } \\
\hline$\leq 70 \%$ & 1 & & & & 1 & & & \\
\hline$>70 \%$ & $0.4(0.2-1.1)$ & 0.09 & $0.3(0.1-0.8)$ & 0.03 & $0.5(0.3-0.9)$ & 0.03 & $0.4(0.2-0.7)$ & 0.02 \\
\hline \multicolumn{9}{|c|}{ T-classification } \\
\hline $\mathrm{T} \leq 2$ & 1 & & & & 1 & & & \\
\hline$T>2$ & $2.4(0.8-6.8)$ & 0.08 & $1.5(0.4-5.0)$ & 0.48 & $1.4(0.7-2.8)$ & 0.31 & NA & NA \\
\hline \multicolumn{9}{|c|}{ N-classification } \\
\hline NO & 1 & & & & 1 & & & \\
\hline $\mathrm{N}+$ & $2.6(0.9-7.3)$ & 0.06 & $4.4(1.2-15.6)$ & 0.02 & $1.4(0.7-2.7)$ & 0.33 & NA & NA \\
\hline \multicolumn{9}{|c|}{ Time to first metastasis (months) } \\
\hline$<12$ & 1 & & & & 1 & & & \\
\hline$\geq 12$ & $0.3(0.1-0.9)$ & 0.03 & $0.2(0.1-0.7)$ & 0.01 & $0.6(0.3-1.2)$ & 0.14 & NA & NA \\
\hline \multicolumn{9}{|c|}{ No. of metastases before SBRT } \\
\hline$<3$ & 1 & & & & 1 & & & \\
\hline$\geq 3$ & $1.4(0.6-3.3)$ & 0.42 & NA & NA & $2.6(1.3-5.1)$ & 0.005 & $2.7(1.4-5.4)$ & 0.003 \\
\hline \multicolumn{9}{|c|}{ No. of affected organs } \\
\hline 1 & 1 & & & & 1 & & & \\
\hline$>1$ & $1.6(0.7-3.9)$ & 0.24 & NA & NA & $1.1(0.5-1.9)$ & 0.97 & NA & NA \\
\hline \multicolumn{9}{|c|}{ Systemic therapy before SBRT } \\
\hline Yes & 1 & & & & 1 & & & \\
\hline No & $1.4(0.3-6.3)$ & 0.65 & NA & NA & $1.4(0.5-4.1)$ & 0.48 & NA & NA \\
\hline
\end{tabular}

NA not assessed, HR Hazard ratio, Cl confidence interval, CRC colorectal cancer, KPS Karnofsky performance status, SBRT stereotactic body radiotherapy

53 Gy and a median $\mathrm{BED}_{\max }$ of $81 \mathrm{~Gy}$ ) with excellent 1and 2-year $\mathrm{LC}$ rates of 89 and $83 \%$, implying that BED < 100 Gy using SFRS might be sufficient for durable control in small lung lesions. This observation, however, contradicts the findings of other studies, where BED < $100 \mathrm{~Gy}$ was found to be a negative prognostic factor for LC. Ricco et al. analyzed whether different lung metastases volumes and BED were associated with treatment outcomes [17]. In this study, lesions after SBRT with $\mathrm{BED} \geq 100 \mathrm{~Gy}$ reached better LC rates. Moreover, in the group with BED $\geq 100$ Gy smaller metastases (volume < $11 \mathrm{~cm}^{3}$ ) were linked to improved LC and OS rates. The median number of fractions employed was 3 (range: 1-
8), how many lesions were treated with SFRS remains unclear. Other trials rarely report on the significance of BED and fractionation regimens in terms of treatment outcome for metastases according to their size $[9,12]$. Nevertheless, the existing data on size-adapted SFRS for lung metastases as well as primary lung tumors is promising with 1 year LC rates varying from $89.1-93.4 \%$ [15, 21-23]. However, diverse measurement units or target volumes describing metastases size (e.g. diameter, GTV, PTV) found in the literature make it difficult to categorize lesions or to identify the optimal dose. Randomized, prospective studies are needed to determine which fractionation schedule is the most suitable for 
Table 7 Overall survival and local control rates after SFRS/fSBRT or pulmonary metastasectomy according to various studies

\begin{tabular}{|c|c|c|c|c|c|c|c|c|c|c|}
\hline \multirow[t]{2}{*}{ Reference } & \multirow[t]{2}{*}{ Study design } & \multirow[t]{2}{*}{ Year } & \multirow{2}{*}{$\begin{array}{l}\text { No. } \\
\text { Patients }\end{array}$} & \multirow{2}{*}{$\begin{array}{l}\text { Primary } \\
\text { tumor }\end{array}$} & \multirow[t]{2}{*}{ No. of LM } & \multirow[t]{2}{*}{ Treatment } & \multicolumn{2}{|c|}{ Overall survival } & \multicolumn{2}{|c|}{ Local control } \\
\hline & & & & & & & 1-year (\%) & 2 -years (\%) & 1-year (\%) & 2-years (\%) \\
\hline Nuyttens et al. [8] & $\begin{array}{l}\text { Phase } 2 \\
\text { study }\end{array}$ & 2015 & 30 & Various & $1-5$ & SFRS/fSBRT & - & 63 & 79 & - \\
\hline Rieber J et al. [9] & Retrospective & 2016 & 700 & Various & $42 \%$ single & SFRS/fSBRT & 75.1 & 54.4 & - & 81.2 \\
\hline Navarria et al. [10] & Retrospective & 2014 & 76 & Various & $1-5$ & fSBRT & 84.1 & 73 & 95 & 89 \\
\hline $\begin{array}{l}\text { Sharma A. et al. } \\
{[11,12]}\end{array}$ & Retrospective & 2018 & 206 & Various & $1-5$ & SFRS/fSBRT & - & 63 & - & 85 \\
\hline $\begin{array}{l}\text { Widder J et al. } \\
\text { [13] }\end{array}$ & Retrospective & 2013 & 110 & Various & $3-5$ & $\begin{array}{l}\text { fSBRT } 42, \\
\text { PME } 68\end{array}$ & $\begin{array}{l}\text { SBRT: } 87 \\
\text { PME: } 98\end{array}$ & $\begin{array}{l}\text { SBRT: } 86 \text { PME: } \\
74\end{array}$ & $\begin{array}{l}\text { SBRT: } 94 \\
\text { PME: } 93\end{array}$ & $\begin{array}{l}\text { SBRT:94 PME: } \\
90\end{array}$ \\
\hline Sapir et al. [14] & Retrospective & 2016 & 78 & Sarcoma & - & $\begin{array}{l}\text { SBRT 26, } \\
\text { PME } 127\end{array}$ & - & $\begin{array}{l}\text { SBRT: } 57.9, \\
\text { PME: } 62.2\end{array}$ & - & $\begin{array}{l}\text { SBRT: } 97.4 \\
\text { PME: } 96.8\end{array}$ \\
\hline Filippi et al. [15] & Retrospective & 2014 & 67 & Various & $1-5$ & SFRS & 85.1 & 70.5 & 93 & 88.1 \\
\hline Agolli L [16] & Retrospective & 2017 & 44 & CRC & $\begin{array}{l}1-4(61 \% \\
\text { single) }\end{array}$ & SFRS/fSBRT & - & 67.7 & 68.8 & 60.2 \\
\hline Present study & Retrospective & 2019 & 52 & Various & Median 2 & SFRS/fSBRT & 84 & 71 & $\begin{array}{l}\text { SFRS } 89 \\
\text { fSBRT } 83\end{array}$ & $\begin{array}{l}\text { SFRS } 83, \text { fSBRT } \\
59\end{array}$ \\
\hline
\end{tabular}

LM lung metastases, SBRT stereotactic body radiotherapy, SFRS single fraction radiosurgery, fSBRT fractionated stereotactic radiotherapy

lung metastases according to the size in terms of therapy outcomes, toxicity and patient's compliance.

In the current study, 1- and 2-year LC rates for metastases from CRC compared with non-CRC were significantly worse. Recently, Jingu et al. investigated the impact of primary tumor histology on LC rates after SBRT for lung metastases in a metanalysis and systematic review. Analysis of 1920 patients (619 with CRC, 1301 non-CRC) showed that LC was significantly inferior in the CRC group $(p<0.00001)$. In addition, the dose escalation (BED > $130 \mathrm{~Gy}$ ) was associated with decreased local recurrences [24]. Furthermore, Ahmed and colleagues concluded that lung metastases from rectal carcinoma are related with increased radio-resistance, and therefore are more likely to relapse after SBRT. The authors recommend dose escalation with BED > 100 Gy for radio-resistant tumors in order to improve treatment outcomes [25]. In the present study, the median BED for relapsed metastases from rectal cancer was $87.5 \mathrm{~Gy}$ (range: 56-124.8), suggesting that an insufficient dose for this histology may be responsible for lower LC rates in patients with CRC. Therefore, SBRT with BED $<100$ Gy should be used with caution in patients with lung oligometastases from rectal cancer.

We found time to the first metastasis $\geq 12$ months, KPS $>70 \%$ and N0 to be independent favorable prognostic factors for OS. Metachronous metastases with longer metastasis free interval are associated with indolent tumor histology and thus are frequently linked to better outcomes, with the favoring time to metastasis diagnose varying from $\geq 2$ months to $\geq 75$ months depending on the primary tumor type [26-28]. Furthermore, in agreement with our results good performance score before initiation of the SBRT was linked to better survival in various studies $[29,30]$. Absence of lymph node involvement was addressed as a prognostic factor mostly in series on oligometastatic lung cancer [27, 31]. Unlike our finding, no prognostic value of $\mathrm{N}$ classification was reported in studies with cohorts of heterogenous primary tumor type, therefore this finding must be interpreted carefully. Despite the small sample size, we identified two commonly reported prognostic factors that might be useful for selecting oligometastatic patients for curative SBRT.

The major limitation of this study is its retrospective design with inhomogeneous primary tumor types and the limited number of patients. Therefore, neither a subgroup analysis based on metastasis histology nor an analysis of the effects of dose escalation was performed. Treatment planning calculations with Ray-Tracing, Pencil Beam or Monte Carlo dose algorithms for lung might produce differences in dose distribution for target and organs at risk. However, there was no difference detected in the treatment outcomes in metastases planed with different treatment algorithms. Since multiple metastases in the same patient were treated with different fractionation, finding the prognostic value of SFRS vs. fSBRT for survival outcomes was not feasible.

\section{Conclusions}

KPS $>70 \%$, longer time to first metastasis and absence of locoregional lymph node metastases were found to be positive predictive factors for OS in patients with lung oligometastases after SBRT. Long-term LC and low toxicity rates were achieved after short SBRT schedules.

\section{Abbreviations}

BED: Biologically effective dose; CRC: Colorectal cancer; Cl: Confidence interval; CT: Computed tomography; CTV: Clinical treatment volume; 
CK: Cyberknife; DMFS: Distant metastases-free survival; EQD2: Equivalent dose in $2 \mathrm{~Gy}$ fractions; fSBRT: Fractionated stereotactic body radiotherapy; GTV: Gross tumor volume; HNC: Head and neck cancer; HI: Hazard ratio; IGTV: Internal gross tumor volume; LC: Local control; non-CRC: Noncolorectal cancer; NSCLC: Non-small-cell lung cancer; OS: Overall survival; PFS: Progression-free survival; PTV: Planning treatment volume; RCC: Renal cell carcinoma; SFRS: Single fraction radiosurgery; SBRT: Stereotactic body radiotherapy

\section{Acknowledgments}

Not applicable.

\section{Availability of data and material}

The datasets used and/or analyzed during the current study are available from the corresponding author on reasonable request.

\section{Authors` contributions}

GK acquired, analyzed and interpreted the patient data, conducted the statistical analysis, drafted the manuscript. CS2, IT and MK provided the idea for the study. CS1, CS2 and IT contributed to data interpretation and manuscript writing. AK provided technical support, preparation of figures and critical review of the manuscript. GK, MK, AG, VB, CS1 and CS2 were responsible for treatment, collection of patient data and follow-up. CS1 and CS2 contributed equally. All authors read and approved the final version of the manuscript.

\section{Funding}

This study was supported by scholarship for Goda Kalinauskaite from Berliner Krebsgesellschaft, Ernst von Leyden-Stipendium.

\section{Ethics approval and consent to participate}

Analysis of patient data was approved by the institutional medical ethics committee of the Charite - Universitätsmedizin Berlin (EA1/214/16). Because of retrospective nature of this study we did not obtain written nor verbal informed consents from the patients.

\section{Consent for publication}

Not applicable.

\section{Competing interests}

The authors declare that they have no competing interests.

\section{Author details}

'Department of Radiation Oncology and Radiotherapy, Charité Universitätsmedizin Berlin, Augustenburger Platz 1, 13353 Berlin, Germany. ${ }^{2}$ Charité CyberKnife Center, Charité - Universitätsmedizin Berlin, Augustenburger Platz 1, 13353 Berlin, Germany. ${ }^{3}$ The Translational Radiooncology and Radiobiology Research Laboratory, Charité Universitätsmedizin Berlin, Berlin, Germany.

\section{Received: 17 July 2019 Accepted: 23 April 2020}

Published online: 11 May 2020

\section{References}

1. Chaffer $\mathrm{CL}$, Weinberg RA. A perspective on cancer cell metastasis. Science. 2011;331(6024):1559-64.

2. Hellman S, Weichselbaum RR. Oligometastases. J Clin Oncol. 1995;13:8-10.

3. Lindsay DP, Caster JM, Wang K, Myung JH, Chen RC, Chera B, et al. Nanotechnology-based quantification of circulating tumor cells in oligometastatic patients undergoing definitive radiation therapy. Int J Radiat Oncol Biol Phys. 2017;99(2):S51.

4. Herold CJ, Bankier AA, Fleischmann D. Lung metastases. Eur Radiol. 1996; 6(5):596-606.

5. Budczies J, von Winterfeld M, Klauschen F, Bockmayr M, Lennerz JK, Denkert C, et al. The landscape of metastatic progression patterns across major human cancers. Oncotarget. 2015;6(1):570-83.

6. Lodeweges JE, Klinkenberg TJ, Ubbels JF, Groen HJM, Langendijk JA, Widder J. Long-term outcome of surgery or stereotactic radiotherapy for lung Oligometastases. J Thorac Oncol. 2017;12(9):1442-5.

7. Filippi AR, Guerrera F, Badellino S, Ceccarelli M, Castiglione A, Guarneri A, et al. Exploratory analysis on overall survival after either surgery or stereotactic radiotherapy for lung Oligometastases from colorectal Cancer. J Clin Oncol. 2016;28(8):505-12.

8. Nuyttens JJ, van der Voort van Zyp NC, Verhoef C, Maat A, van Klaveren RJ, van der Holt B, et al. Stereotactic body radiation therapy for oligometastases to the lung: a phase 2 study. Int J Radiat Oncol Biol Phys. 2015;91(2):337-43.

9. Rieber J, Streblow J, UhImann L, Flentje M, Duma M, Ernst I, et al. Stereotactic body radiotherapy (SBRT) for medically inoperable lung metastases-a pooled analysis of the German working group "stereotactic radiotherapy". Lung Cancer. 2016;97:51-8.

10. Navarria P, Ascolese AM, Tomatis S, Cozzi L, De Rose F, Mancosu B, et al. Stereotactic body radiotherapy (sbrt) in lung oligometastatic patients: role of local treatments. Radiat Oncol. 2014;9(1):91.

11. Sharma A, Duijm M, Oomen-de Hoop E, Aerts JG, Verhoef C, Hoogeman M, et al. Survival and prognostic factors of pulmonary oligometastases treated with stereotactic body radiotherapy. Acta Oncol. 2019;58(1):74-80.

12. Sharma A, Duijm M, Oomen-de Hoop E, Aerts JG, Verhoef C, Hoogeman M, et al. Factors affecting local control of pulmonary oligometastases treated with stereotactic body radiotherapy. Acta Oncol. 2018;57(8):1031-7.

13. Widder J, Klinkenberg TJ, Ubbels JF, Wiegman EM, Groen HJ, Langendijk JA. Pulmonary oligometastases: Metastasectomy or stereotactic ablative radiotherapy? Radiother Oncol. 2013;107(3):409-13.

14. Sapir E, Tao Y, Lin T, Kollar L, Schipper M, Chugh R, et al. Surgical resection or stereotactic body radiation therapy for sarcoma patients with pulmonary metastases. Int J Radiat Oncol Biol Phys. 2016;96(2):S26.

15. Filippi AR, Badellino S, Guarneri A, Levis M, Botticella A, Mantovani C, et al. Outcomes of single fraction stereotactic ablative radiotherapy for lung metastases. Technol Cancer Res Treat. 2014;13(1):37-45.

16. Agolli L, Bracci S, Nicosia L, Valeriani M, De Sanctis V, Osti MF. Lung metastases treated with stereotactic ablative radiation therapy in Oligometastatic colorectal Cancer patients: outcomes and prognostic factors after long-term follow-up. Clin Colorectal Cancer. 2017;16(1):58-64.

17. Ricco A, Davis J, Rate W, Yang J, Perry D, Pablo J, et al. Lung metastases treated with stereotactic body radiotherapy: the RSSearch ${ }^{\oplus}$ patient Registry's experience. Radiat Oncol. 2017;12(1):35.

18. Oh Y, Taylor S, Bekele BN, Debnam JM, Allen PK, Suki D, et al. Number of metastatic sites is a strong predictor of survival in patients with nonsmall cell lung cancer with or without brain metastases. Cancer. 2009;115(13): 2930-8.

19. Wang Z, Kong Q-T, Li J, Wu X-H, Li B, Shen Z-T, et al. Clinical outcomes of cyberknife stereotactic radiosurgery for lung metastases. J Thorac Dis. 2015; 7(3):407-12.

20. Siva S, Kron T, Bressel M, Haas M, Mai T, Vinod S, et al. A randomized phase II study of stereotactic ablative body radiotherapy for metastases to the lung (TROG 13.01 SAFRON II) (SAFRON II). BMC Cancer. 2016;16:183.

21. Ost MF, Carnevale A, Valeriani M, De Sanctis V, Minniti G, Cortesi E, et al. Clinical outcomes of single dose stereotactic radiotherapy for lung metastases. Clin Lung Cancer. 2013;14(6):699-703.

22. Trakul N, Chang CN, Harris J, Chapman C, Rao A, Shen J, et al. Tumor volume-adapted dosing in stereotactic ablative radiotherapy of lung tumors. Int J Radiat Oncol Biol Phys. 2012;84(1):231-7.

23. Videtic GM, Hu C, Singh AK, Chang JY, Parker W, Olivier KR, et al. A randomized phase 2 study comparing 2 stereotactic body radiation therapy schedules for medically inoperable patients with stage i peripheral nonsmall cell lung cancer: nrg oncology rtog 0915 (ncctg n0927). Int J Radiat Oncol Biol Phys 2015;93(4):757-64.

24. Jingu K, Matsushita H, Yamamoto T, Umezawa R, Ishikawa Y, Takahashi N, et al. Stereotactic radiotherapy for pulmonary oligometastases from colorectal cancer: a systematic review and meta-analysis. Technol Cancer Res Treat. 2018;17:1533033818794936.

25. Ahmed KA, Scott JG, Arrington JA, Naghavi AO, Grass GD, Perez BA, et al. Radiosensitivity of lung metastases by primary histology and implications for stereotactic body radiation therapy using the genomically adjusted radiation dose. J Thorac Oncol. 2018;13(8):1121-7.

26. Hong JC, Ayala-Peacock DN, Lee J, Blackstock AW, Okunieff P, Sung MW, et al. Classification for long-term survival in oligometastatic patients treated with ablative radiotherapy: a multi-institutional pooled analysis. PLoS One. 2018;13(4):e0195149.

27. Ashworth AB, Senan S, Palma DA, Riquet M, Ahn YC, Ricardi U et al. An individual patient data metaanalysis of outcomes and prognostic factors after treatment of oligometastatic non-small-cell lung cancer. Clin Lung Cancer 2014;15(5):346-55. 
28. Inoue T, Katoh N, Aoyama H, Onimaru R, Taguchi H, Onodera S et al. Clinical outcomes of stereotactic brain and/or body radiotherapy for patients with oligometastatic lesions. Jpn J Clin Oncol. 2010;40(8):788-94.

29. Flannery TW, Suntharalingam M, Regine WF, Chin LS, Krasna MJ, Shehata MK, et al. Long-term survival in patients with synchronous, solitary brain metastasis from non-small-cell lung cancer treated with radiosurgery. Int J Radiat Oncol Biol Phys. 2008;72(1):19-23.

30. Lancia A, Ingrosso G, Carosi A, Di Murro L, Giudice E, Cicchetti S, et al. Oligometastatic cancer: stereotactic ablative radiotherapy for patients affected by isolated body metastasis. Acta Oncol. 2017;56(11):1621-5.

31. Li S, Zhu R, Li D, Li N, Zhu X. Prognostic factors of oligometastatic non-small cell lung cancer: a meta-analysis. J Thoracic Dis. 2018;10(6):3701-13.

\section{Publisher's Note}

Springer Nature remains neutral with regard to jurisdictional claims in published maps and institutional affiliations.

Ready to submit your research? Choose BMC and benefit from:

- fast, convenient online submission

- thorough peer review by experienced researchers in your field

- rapid publication on acceptance

- support for research data, including large and complex data types

- gold Open Access which fosters wider collaboration and increased citations

- maximum visibility for your research: over $100 \mathrm{M}$ website views per year

At $\mathrm{BMC}$, research is always in progress.

Learn more biomedcentral.com/submissions 